\title{
Genome Size and Ploidy Levels of Cercis (Redbud) Species, Cultivars, and Botanical Varieties
}

\author{
David J. Roberts ${ }^{1}$ and Dennis J. Werner ${ }^{2}$ \\ Department of Horticultural Science, North Carolina State University, \\ Box 7609, Raleigh, NC 27695-7609
}

Additional index words. DNA content, flow cytometry, plant breeding, systematics, taxonomy

\begin{abstract}
Cercis is an ancient member of Fabaceae, often cultivated as an ornamental tree, and can be found in numerous regions around the world. Previous studies have reported Cercis canadensis as being diploid with $2 n=2 x=14$. However, there have been no further investigations into ploidy and genome size variation among Cercis taxa. A study was conducted to evaluate the relative genome size and ploidy levels of numerous species, cultivars, and botanical varieties of Cercis, representing taxa found in North America, Asia, and the Middle East. In addition, the genome size of Bauhinia forficata, a close relative of Cercis, was also determined. Genome size estimates (2C values) were determined by calculating the mean fluorescence of stained nuclei via flow cytometry. Propidium iodide was used as the staining agent and Glycine max was used as an internal standard for each taxon analyzed. Genome size estimates for all Cercis sampled ranged from 0.70 to $0.81 \mathrm{pg}$ with an average size of $0.75 \mathrm{pg}$. The genome size of $B$. forficata was found to be smaller than any other Bauhinia sp. currently on record, with an average size of $0.87 \mathrm{pg}$. This study confirmed an initial estimation of the genome size of Cercis chinensis and found that floral buds of Cercis proved to be an excellent source of plant tissue for obtaining intact nuclei. All species, botanical varieties, and cultivars of Cercis surveyed for this study had remarkably similar genome sizes despite their wide range of distribution. This information can facilitate a better understanding of phylogenetic relationships within Cercideae and Cercis specifically.
\end{abstract}

The genus Cercis L. (Fabaceae: Caesalpinoideae: Cercideae), also known as redbud, is a valuable commodity in the North American landscape industry and can be found growing in temperate environments across the globe. Cercis consists of $\approx 10$ species (Davis et al., 2002; Fritsch et al., 2009), which can be found in North America (C. canadensis L., Cercis occidentalis Torr. ex A. Gray), Asia (C. chinensis Bunge, Cercis chingii Chun, Cercis chuniana P.F. Metcalf, Cercis gigantea W.C. Cheng \& Keng f., Cercis glabra Pamp, Cercis racemosa Oliv., and Cercis siliquastrum L.), and the Middle East (Cercis griffithii Boiss.). Redbud is recognized for a variety of interesting morphological characteristics, many of which make them ideal

Received for publication 25 Jan. 2016. Accepted for publication 23 Feb. 2016.

This research was funded by the NC Agricultural Research Service, J. Frank Schmidt Family Charitable Foundation, and the North Carolina Nursery and Landscape Association.

Technical assistance provided by Tom Ranney, Nathan Lynch, Sarah Seschuet, Kim Shearer-Lattier, and Jason Lattier is gratefully acknowledged. Special thanks to Richard Olsen and David Kidwell-Slak (United States National Arboretum) for providing samples of Cercis siliquastrum and to Charles R. Keith for providing samples of $C$. siliquastrum, C. Occidentalis, and C. griffithii.

${ }^{1}$ Graduate student.

${ }^{2}$ Corresponding author. E-mail: dennis_werner@ ncsu.edu. ornamental specimens. Valuable insight into angiosperm evolution can be obtained through genetic surveys of this valuable landscape commodity.

Fabaceae, one of the most successful lineages of flowering plants (Legume Phylogeny Working Group et al., 2013) has long been the subject of genomics and genetic research. In particular, species like Lotus japonicus (Regel) K. Larsen and Medicago truncatula Gaertner have been adopted internationally as genetic models for legume-based research thanks to their model characteristics (Udvardi et al., 2005). Caesalpinoideae, a subfamily in which Cercideae resides, contains much of the evolutionary and genetic diversity found in all of Fabaceae. However, recent studies have focused on cultivated legume crops, all of which have diverged relatively recently (Young et al., 2003). This information covers only a fraction of the great diversity that can be found within Fabaceae (Doyle and Luckow, 2003) and could be further supplemented by studying a basal, non-nitrogen fixing member of Fabaceae such as Cercis.

Cercis, an ancient member of Caesalpinoideae, has fossil records that date back to the Eocene era (Jia and Manchester, 2014), and is therefore a prime candidate for a comprehensive study of genome size as it relates to legume systematics and taxonomy. Most aspects of legume biology, from ploidy number to floral diversity, can be further examined through the evolutionary relationships that exist among leguminous taxa (Young et al., 2003). This information could grant valuable insight into species evolution and provide potential breeding applications (Rounsaville and Ranney, 2010) in future Cercis hybridization projects.

Information derived from a genome survey of Cercis will be useful as it relates to a better understanding of the evolution of genome size and ploidy distribution within the legumes. Three cultivars of Cercis warrant particular interest in regard to ploidy variation. Traveller is a unique cultivar of C. canadensis var. texensis possessing both male and female sterility. The basis of this sterility is unknown, but potentially could be based on triploidy. Triploid plants often have reduced fertility or sterility. Likewise, 'Don Egolf' is a female sterile form of C. chinensis and will be investigated to determine if its sterility is due to triploidy. Finally, 'Tom Thumb' a diminutive sterile form of $C$. canadensis with extremely small leaves and flowers will be investigated to determine if its unique characters are potentially due to haploidy. Haploid plants have been shown to exhibit dwarfism in other woody species (Yahata et al., 2005). This survey will also contribute to the knowledge of the taxonomic relationship of Bauhinia to redbud. Cercis has been documented as having seven chromosome pairs with $2 n=2 x=14$ (Curtis, 1976; Goldblatt, 1981). Bauhinia is thought to be a tetraploid $(2 n=4 x=28)$ relative of Cercis (Doyle and Luckow, 2003) with 14 chromosome pairs (Turner, 1956). As the closest living relative of redbud (Coskun and Parks, 2009), Bauhinia will serve as an interesting comparison with the relative DNA estimations of Cercis in this study.

Cercis chinensis possesses a relatively small genome size of 350 million bps $(\mathrm{Mb})$ (De Mita et al., 2014), which corresponds with the phylogenetic position of significant antiquity (Zou et al., 2008) that Cercis occupies within Fabaceae. Except for $C$. chinensis, there are currently no other reports of genome size of Cercis. The objectives of this study were to examine the genome size of a comprehensive collection of species, botanical varieties, and cultivars of Cercis. Additionally, the genome size of 'Tom Thumb', demonstrating morphological characters suggesting haploidy, and of 'Traveller' and 'Don Egolf', sterile cultivars suggesting triploidy, will be examined.

\section{Materials and Methods}

Plant material. For the purposes of this study, nine species of Cercis and one species of Bauhinia (B. forficata Link) were surveyed for relative DNA content. A total of 30 taxa (Table 1) were surveyed, including three botanical varieties of Cercis: $C$. canadensis var. canadensis, $C$. canadensis var. mexicana (Rose) M. Hopkins, and C. canadensis var. texensis (S. Watson) M. Hopkins. This survey also included a number of cultivars and hybrids that exhibit the full spectrum of morphological variation found in Cercis. Glycine $\max \mathrm{L}$. (2C DNA $=2.25 \mathrm{pg}$ ) was 
Table 1. Genome size and estimated ploidy levels of Cercis species, cultivars, and botanical varieties.

\begin{tabular}{|c|c|c|c|c|}
\hline Taxa & $\begin{array}{c}\text { Source }^{z} \text {-accession } \\
\text { no. }\end{array}$ & $\begin{array}{l}\text { 2C genome } \\
\text { size }(\mathrm{pg})^{\mathrm{y}}\end{array}$ & $\begin{array}{l}\text { Mean } 1 \mathrm{C} \text { genome } \\
\text { size (pg) by species }\end{array}$ & $\begin{array}{c}\text { Estimated ploidy } \\
\text { level }(x)\end{array}$ \\
\hline Cercis canadensis & JCRA -050030 & $0.76 \pm 0.01$ & $0.37 \pm 0.01$ & $2 n=2 x$ \\
\hline C. canadensis 'Ace of Hearts' & JCRA -040037 & $0.72 \pm 0.00$ & & $2 n=2 x$ \\
\hline C. canadensis 'Appalachia Red' & JCRA -100164 & $0.77 \pm 0.01$ & & $2 n=2 x$ \\
\hline C. canadensis 'Dwarf White' & JCRA -020083 & $0.76 \pm 0.01$ & & $2 n=2 x$ \\
\hline C. canadensis 'Flame' & JCRA-990614 & $0.71 \pm 0.01$ & & $2 n=2 x$ \\
\hline C. canadensis 'Floating Clouds' & JCRA -050027 & $0.74 \pm 0.01$ & & $2 n=2 x$ \\
\hline C. canadensis 'Forest Pansy' & JCRA_-980909 & $0.77 \pm 0.01$ & & $2 n=2 x$ \\
\hline C. canadensis 'Greswan' & JCRA-100497 & $0.72 \pm 0.01$ & & $2 n=2 x$ \\
\hline C. canadensis 'Hearts of Gold' & JCRA -040050 & $0.73 \pm 0.00$ & & $2 n=2 x$ \\
\hline C. canadensis ' $\mathrm{JN} 2$ ' & JCRA -100498 & $0.75 \pm 0.01$ & & $2 n=2 x$ \\
\hline C. canadensis 'Little Woody' & JCRA -040036 & $0.78 \pm 0.03$ & & $2 n=2 x$ \\
\hline C. canadensis 'Ruby Falls' & JCRA -100167 & $0.74 \pm 0.02$ & & $2 n=2 x$ \\
\hline C. canadensis 'Silver Cloud' & JCRA -030265 & $0.74 \pm 0.01$ & & $2 n=2 x$ \\
\hline C. canadensis 'Tom Thumb' & JCRA -050031 & $0.76 \pm 0.01$ & & $2 n=2 x$ \\
\hline C. canadensis var. mexicana & JCRA - xx041 & $0.72 \pm 0.01$ & & $2 n=2 x$ \\
\hline C. canadensis var. mexicana $\mathrm{NC} 4$ & $\begin{array}{l}\text { Unaccessioned JCRA } \\
\text { selection }\end{array}$ & $0.78 \pm 0.01$ & & $2 n=2 x$ \\
\hline C. canadensis var. texensis 'Oklahoma' & JCRA -090011 & $0.77 \pm 0.02$ & & $2 n=2 x$ \\
\hline C. canadensis var. texensis 'Traveller' & JCRA-960536 & $0.74 \pm 0.01$ & & $2 n=2 x$ \\
\hline C. canadensis [Texensis Group] 'Merlot' & $\mathrm{JCRA}-090079$ & $0.72 \pm 0.02$ & & $2 n=2 x$ \\
\hline C. chinensis & $\mathrm{JCRA}-\mathrm{xx} 044$ & $0.76 \pm 0.01$ & $0.37 \pm 0.00$ & $2 n=2 x$ \\
\hline C. chinensis 'Don Egolf' & JCRA -050037 & $0.74 \pm 0.01$ & & $2 n=2 x$ \\
\hline C. chinensis 'Shirobana' & JCRA -020089 & $0.74 \pm 0.01$ & & $2 n=2 x$ \\
\hline C. chingii & JCRA -020086 & $0.81 \pm 0.01$ & $0.40 \pm 0.00$ & $2 n=2 x$ \\
\hline C. gigantea & JCRA -020079 & $0.81 \pm 0.00$ & $0.41 \pm 0.00$ & $2 n=2 x$ \\
\hline C. glabra & JCRA -920545 & $0.75 \pm 0.01$ & $0.38 \pm 0.00$ & $2 n=2 x$ \\
\hline C. glabra 'Celestial Plum' & JCRA -090316 & $0.77 \pm 0.00$ & & $2 n=2 x$ \\
\hline C. griffithii & CRKA & $0.70 \pm 0.01$ & $0.35 \pm 0.00$ & $2 n=2 x$ \\
\hline C. occidentalis & CRKA & $0.74 \pm 0.01$ & $0.37 \pm 0.00$ & $2 n=2 x$ \\
\hline C. racemosa & JCRA -080062 & $0.78 \pm 0.01$ & $0.39 \pm 0.01$ & $2 n=2 x$ \\
\hline C. siliquastrum & USNA-118kj 37350 & $0.77 \pm 0.02$ & $0.38 \pm 0.01$ & $2 n=2 x$ \\
\hline Bauhinia florficata & PDN & $0.87 \pm 0.01$ & $0.43 \pm 0.00$ & $2 n=2 x$ \\
\hline
\end{tabular}

${ }^{\mathrm{z} J C R A}=$ JC Raulston Arboretum, Raleigh, NC; USNA = United States National Arboretum, Washington, DC; CRKA = Charles R. Keith Arboretum, Chapel Hill, $\mathrm{NC} ; \mathrm{PDN}=$ Plant Delights Nursery, Raleigh, NC.

${ }^{y}$ Genome size for each taxon was determined from two independent analyses conducted in Jan. 2014 and Jan. 2015. At each sampling date, two subsamples were prepared for each taxon analyzed. Values shown represent the mean and the SE of the mean of the two sampling dates.

used as the internal standard for all taxa surveyed.

Sample preparation. Newly expanded leaf tissue of Cercis proved recalcitrant to obtaining adequate quantities of intact nuclei. Therefore, a protocol modified from Dolezel et al. (2007) was employed for the assay procedure. Floral buds were used as plant tissue for all Cercis sampled. Plant tissue was obtained from the U.S. National Arboretum (Washington, DC), the JC Raulston Arboretum (Raleigh, NC), and the Charles R. Keith Arboretum (Chapel Hill, NC). All taxa were assayed once in Jan. 2014 and again in Jan. 2015.

Expanding floral buds were harvested from bud sticks collected in late January and forced for $\approx 10-14 \mathrm{~d}$ under greenhouse conditions. For each sample, about six to eight floral buds were collected and placed into a $60 \times 15 \mathrm{~mm}$ petri dish containing damp filter paper. Buds were descaled and refrigerated at $4{ }^{\circ} \mathrm{C}$ before sample preparation. New but fully expanded leaves obtained from container-grown G. max plants grown under greenhouse conditions were used as the internal standard for each sample. Sample preparation required about three floral buds from the Cercis sample to be chopped with $1 \mathrm{~cm}^{2}$ of leaf tissue from the G. max standard. Combined plant tissues were chopped finely with a double-edged razor blade (Personna stainless steel double edge prep blades,
Edgewell Personal Care, Shelton, CT) in a $60 \times 15 \mathrm{~mm}$ petri dish. Chopped plant material was gently agitated in $500 \mu \mathrm{L}$ of nuclei extraction buffer (Cystain ${ }^{\circledR}$ PI Absolute $\mathrm{P}$, Sysmex, Germany) and after $\approx 60 \mathrm{~s}$ of incubation, suspension was poured through a $50-\mu \mathrm{m}$ nylon mesh filter into a small, polystyrene test tube. The resulting nuclei suspension was then stained using $1500 \mu \mathrm{L}$ of propidium iodide staining solution (Cystain ${ }^{\circledR}$ PI Absolute P), prepared by combining $2 \mathrm{~mL}$ staining buffer, $12 \mu \mathrm{L}$ propidium iodide, and $6 \mu \mathrm{L}$ of RNase per sample. Two subsamples were prepared for each taxon analyzed. Stained nuclei suspensions were refrigerated at $4{ }^{\circ} \mathrm{C}$ for $1 \mathrm{~h}$ before being analyzed via flow cytometry. All samples were completely randomized before analysis.

Flow cytometry. Holoploid genome size estimates were determined by measuring the relative fluorescence of stained nuclei via flow cytometry. Analysis of each sample was conducted on a BD LSR II flow cytometer (Becton-Dickson Biosciences, San Jose, CA) operating with a $20-\mathrm{mW}$ argon laser $($ excitation $=488 \mathrm{~nm}$ ). Histograms that display mean fluorescence values were compiled until a minimum cell count of 5000 was achieved for each sample. Cell counts were acquired using BD FACSDiva software (Becton-Dickson Biosciences) and analyzed using FCS Express (De Novo Software, Los Angeles, CA). Holoploid genome size estimates for each sample were calculated as: $2 \mathrm{C}=$ (mean fluorescence of sample $\div$ mean fluorescence of standard $) \times$ ( $2 \mathrm{C}$ value of standard). Chromosome number of diploid $C$. canadensis has been documented as $2 n=2 x=14$ (Curtis, 1976; Goldblatt, 1981) and was compared with genome size estimates and used to infer ploidy of taxa sampled.

\section{Results and Discussion}

Floral buds proved to be an excellent source for obtaining intact nuclei (Fig. 1) and proved to be a more viable option than leaf tissue among all Cercis sampled. Results of flow cytometric analysis show that holoploid genome size estimates among Cercis taxa were relatively small and highly conserved across species, with sizes ranging from 0.70 to $0.81 \mathrm{pg}$ (Table 1) with a mean of $0.75 \mathrm{pg}$. Comparatively, the $2 \mathrm{C}$ genome size estimates of Lotus japonicus and $M$. truncatula (both model organisms) have each been confirmed to be $0.95 \mathrm{pg}$ (Bennett and Leitch, 2011). Previous studies that used foliar tissue estimated the monoploid (1Cx) genome size of $C$. chinensis to be $350 \mathrm{Mb}$ $(0.36 \mathrm{pg})$. This study obtained similar values by using floral bud tissue, with $1 \mathrm{Cx}$ genome size estimates for $C$. chinensis ranging from 356.97 to $381.42 \mathrm{Mb}(0.37-0.39 \mathrm{pg})$ with an average of $371.64 \mathrm{Mb}(0.38 \mathrm{pg})$. 


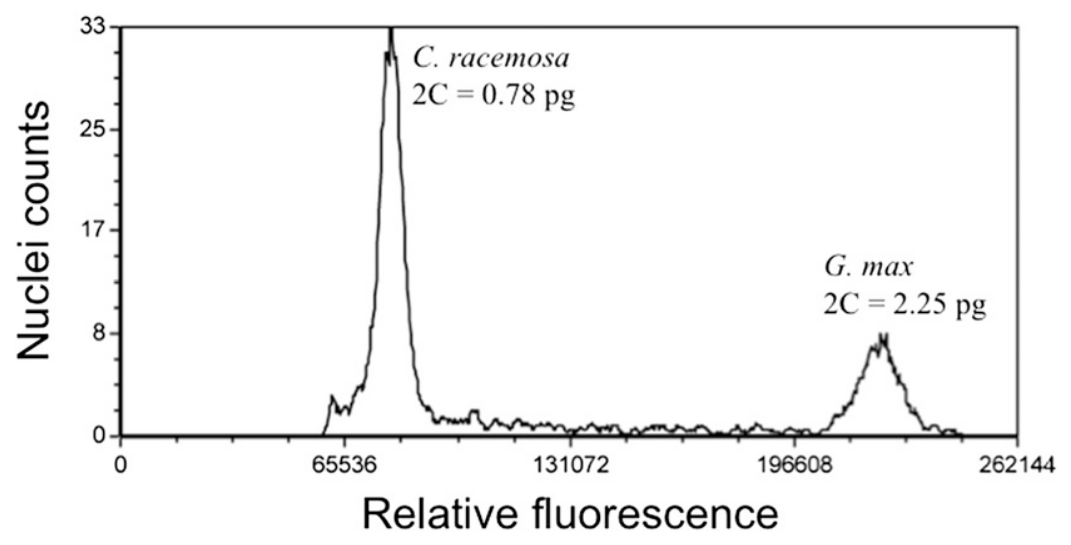

Fig. 1. Histogram displaying mean fluorescence of stained nuclei, obtained from floral buds of Cercis racemosa Olive and leaf tissue of Glycine max L.

A query of the Kew Royal Botanic Garden DNA C-values database (Bennett and Leitch, 2012) shows that Cercis possesses the smallest $2 \mathrm{C}$ genome size ( $0.75 \mathrm{pg}$ on average) of all reported members of Fabaceae, reflecting its antique phylogenetic position. However, the diminutive nature and lack of variability in genome size among all Cercis sp. is surprising given the long temporal and geographic isolation the taxa have experienced. Genome size and variability is thought to increase in size as speciation occurs. Variation in genome size is especially noticeable in species with extensive geographic distribution, high degrees of morphological differentiation, and several subspecific categories (Huang et al., 2013). Interestingly, Cercis sp. meet all of these criteria but have not shown a significant increase in genome size or polyploidization events, as would be expected of such an ancient genus.

The high degree of morphological variation found in Cercis, and the existence of sterility, suggest that several cultivars of particular interest could have arisen from variations in ploidy. However, three specific cultivars subject to genome size estimation, Traveller (sterile), Don Egolf (sterile), and Tom Thumb (very small leaves and flowers) were diploid. The lack of variability in ploidy among Cercis taxa is informative, as ancient polyploidization events have been associated with increases in plant diversity in Fabaceae (Doyle et al., 2012; Schranz et al., 2012; Soltis and Burleigh, 2009; Soltis et al., 2014).

Contrary to previous studies that have reported Bauhinia being a tetraploid relative of Cercis, 2C estimates of B. forficata place its genome size at $0.87 \mathrm{pg}$ (Table 1). If $B$. forficata was tetraploid, one would expect its $2 \mathrm{C}$ genome size to approach $1.4 \mathrm{pg}$, as is the case with Bauhinia monandra Kurz (Ohri et al., 2004). There is evidence of small ancestral genome sizes among angiosperms (Leitch et al., 1998), and it could be that $B$. forficata is a more ancestral member of the genus. It is also possible that most Bauhinia sp. are tetraploid, and that $B$. forficata experienced a reduction in chromosome number. Every major evolutionary line of legume seems to have experienced some degree of descending aneuploidy (Goldblatt, 1981), which could explain the small genome size of $B$. forficata, relative to the rest of the genus. No other studies have reported the genome size or chromosome number of B. forficata and as such, further research into its relationship with other members of Cercideae could prove to be informative.

\section{Conclusions}

Our data confirmed an initial report of the genome size of $C$. chinensis. This study revealed that all Cercis taxa surveyed had remarkably similar genome sizes despite their wide range of phenotypic diversity and wide geographic distribution. Furthermore, all taxa surveyed proved to be diploid, despite our initial hypotheses of potential haploidy in C. canadensis 'Tom Thumb', and potential triploidy in $C$. canadensis var. texensis 'Traveller' and $C$. chinensis 'Don Egolf'. Estimates of 2C genome size among all Cercis surveyed ranged from 0.70 to $0.81 \mathrm{pg}$ with an average size of $0.75 \mathrm{pg}$. Model legumes such as M. truncatula and L. japonicus, both nitrogen fixing species, are known for having "compact" genome sizes, with $2 \mathrm{C}$ values of $\approx 929 \mathrm{Mbp}$ or $0.95 \mathrm{pg}$ (Young et al., 2003). Cercis is an ancient genus possessing a smaller genome size than both M. truncatula and L. japonicus, supporting the hypothesis that a whole genome doubling event occurred shortly after the origin of rhizobial symbiosis in Fabaceae but did not affect more basal legume lineages of Caesalpinoideae (De Mita et al., 2014). Cercis is widely regarded as an out-group of Fabaceae due to its inability to fix nitrogen. The symbiosis that developed between plants and the nitrogen-fixing bacteria known as rhizobia occurred $\approx 60$ million years ago and could be one of the contributing factors that gave rise to more than 19,000 species of legume (De Mita et al., 2014; Doyle, 1998; Doyle et al., 2012; Legume Phylogeny Working Group et al., 2013). As a basal member of the legumes, Cercis was likely external to the evolutionary event that led to the symbiotic relationship with rhizobial bacteria (De Mita et al., 2014). As such, Cercis could prove invaluable in future studies of legume speciation.

\section{Literature Cited}

Bennett, M.D. and I.J. Leitch. 2011. Nuclear DNA amounts in angiosperms: Targets, trends and tomorrow. Ann. Bot. 107:467-590.

Bennett, M.D. and I.J. Leitch. 2012. Plant DNA C-values database (release 6.0). $<\mathrm{http}: / / \mathrm{www}$. kew.org/cvalues/>.

Coskun, F. and C.R. Parks. 2009. A molecular phylogenetic study of red buds (Cercis L., Fabaceae) based on ITS nrDNA sequences. Pak. J. Bot. 41:1577-1586.

Curtis, W.F. 1976. Chromosome counts in Grielum and Cercis. Ann. Mo. Bot. Gard. 63:379-380.

Davis, C.C., P.W. Fritsch, J. Li, and M.J. Donoghue. 2002. Phylogeny and biogeography of Cercis (Fabaceae): Evidence from nuclear ribosomal ITS and chloroplast $n d h F$ sequence data. Syst. Bot. 27:289-302.

De Mita, S., A. Streng, T. Bisseling, and R. Geurts. 2014. Evolution of a symbiotic receptor through gene duplications in the legume-rhizobium mutualism. New Phytol. 201:961-972.

Dolezel, J., J. Greilhuber, and J. Suda. 2007. Estimation of nuclear DNA content in plants using flow cytometry. Nat. Protoc. 9:22332244.

Doyle, J.J. 1998. Phylogenetic perspectives on nodulation: An evolving view of plants and symbiotic bacteria. Trends Plant Sci. 3:473478.

Doyle, J.J. and M.A. Luckow. 2003. The rest of the iceberg. Legume diversity and evolution in a phylogenetic context. Plant Physiol. 131:900-910.

Doyle, J.J., P.S. Soltis, and D.E. Soltis. 2012 Polyploidy and genome evolution. SpringerVerlag, Berlin, Heidelberg, Germany.

Fritsch, P.W., K.W. Larson, and A.M. Schiller. 2009. Taxonomic implications of morphological variation in Cercis canadensis (Fabaceae) from Mexico and adjacent parts of Texas. Syst. Bot. 34:510-520.

Goldblatt, P. 1981. Cytology and the phylogeny of leguminosae, p. 427-464. Advances in legume systematics, part 2. Royal Botanic Gardens, Kew, UK

Huang, H., Y. Tong, Q. Zhang, and L. Gao. 2013. Genome size variation among and within $\mathrm{Ca}$ mellia species by using flow cytometric analysis. PLoS One 8:e64981.

Jia, H. and S.R. Manchester. 2014. Fossil leaves and fruits of Cercis L. (Leguminosae) from the Eocene of Western North America. Intl. J. Plant Sci. 175:601-612.

. Legume Phylogeny Working Group, A. Bruneau, J.J. Doyle, P. Herendeen, C. Hughes, G. Kenicer, G. Lewis, B. Mackinder, R.T. Pennington, M.J. Sanderson, and M.F. Wojciechowski. 2013. Legume phylogeny and classification in the 21 st century: Progress, prospects and lessons for other species-rich clades. Taxon 62:217-248

Leitch, I.J., M.W. Chase, and M.D. Bennett. 1998. Phylogenetic analysis of DNA C-values provides evidence for a small ancestral genome size in flowering plants. Ann. Bot. 82:85-94.

Ohri, D., A. Bhargava, and A. Chaterjee. 2004. Nuclear DNA amounts in 112 tropical hardwoods: New estimates. Plant Biol. 6:555-561.

Rounsaville, T.J. and T.G. Ranney. 2010. Ploidy levels and genome sizes of Berberis L. and 
Mahonia Nutt. species, hybrids, and cultivars. HortScience 45:1029-1033.

Schranz, E., P.P. Edger, and S. Mohammadin. 2012. Ancient whole genome duplications novelty and diversification: The WGD radiation lag-time model. Curr. Opin. Plant Biol. 15:147-153.

Soltis, D.E. and J.G. Burleigh. 2009. Surviving the K-T mass extinction: New perspectives of polyploidization in angiosperms. Proc. Natl. Acad. Sci. U.S.A. 106:5455-5456.
Soltis, D.E., C.J. Visger, and P.S. Soltis. 2014. The polyploid revolution then.... and now: Stebbins revisited. Amer. J. Bot. 101:1057-1078.

Turner, B.L. 1956. Chromosome numbers in the leguminosae. Amer. J. Bot. 43:577-581.

Udvardi, M.K., S. Tabata, M. Parniske, and J. Stougard. 2005. Lotus japonicus: Legume research in the fast lane. Trends Plant Sci. 10:222-228.

Yahata, M., S. Harusaki, H. Komatsu, K. Takami, H. Kunitake, T. Yabuya, K. Yamashita, and
P. Toolapong. 2005. Morphological characterization and molecular verification of a fertile haploid pummelo (Citrus grandis Osbeck). J. Amer. Soc. Hort. Sci. 130:34-40.

Young, N.D., J. Mudge, and T.N. Ellis. 2003 Legume genomes: More than peas in a pod. Curr. Opin. Plant Biol. 6:199-204.

Zou, P., J. Liao, and D. Zhang. 2008. Leaf epidermal micromorphology of Cercis (Fabaceae: Caesalpinioideae). Bot. J. Linn. Soc. 158:539547. 